\title{
Influence of orally and rectally administered propionate on cholesterol and glucose metabolism in obese rats
}

\author{
BY ANNA M. BERGGREN'1 , E. MARGARETA G. L. NYMAN ${ }^{1}$, \\ INGMAR LUNDQUIST ${ }^{2}$ AND INGER M. E. BJÖRCK ${ }^{1}$ \\ ${ }^{1}$ Department of Applied Nutrition and Food Chemistry, Lund University, Chemical Centre, \\ PO Box 124, S-221 00 Lund, Sweden \\ ${ }^{2}$ Department of Pharmacology, Lund University, Sölvegatan 10, S-223 62 Lund, Sweden
}

(Received 4 July 1995 - Revised 8 September 1995 - Accepted 11 October 1995)

\begin{abstract}
It has increasingly been suggested that the short-chain fatty acids (SCFA) acetic, propionic and butyric acids, derived from colonic fermentation of dietary fibre and other indigestible carbohydrates, exert different physiological effects. Formation of propionic acid is discussed in terms of beneficial effects on glucose and cholesterol metabolism. The aim of the present study was to evaluate possible metabolic effects of propionic acid and to differentiate between effects mediated in the upper gastrointestinal tract and those mediated in the hind-gut. For this purpose, obese hyperinsulinaemic (fa/fa) rats were studied during a $19 \mathrm{~d}$ test period. Sodium propionate was either fed orally through the diet $(1 \mathrm{~g} / \mathrm{d})$, or infused rectally $(0.15 \mathrm{~g} / \mathrm{d})$ to animals given diets high in cholesterol $(20 \mathrm{~g} / \mathrm{kg})$ and saturated fat $(130 \mathrm{~g} / \mathrm{kg})$. At the end of the test period total liver cholesterol pools were $20 \%$ lower $(P<0.01)$ in rats given dietary or rectally infused propionate (481 and $484 \mathrm{mg}$ respectively) compared with the control group (614 $\mathrm{mg})$. This was due to lower liver weights $(P<0.05)$ in propionate-treated animals, 15.5 and $15.3 \mathrm{~g}, \mathrm{v} .18 .2 \mathrm{~g}$ in the control group, and no differences were noted in hepatic cholesterol concentrations. The urinary glucose excretion was measured during days 15-19 and was found to be lower $(P<0.05)$ in rats fed with propionate (23 mg) compared with the control group or the group infused rectally (39 and $38 \mathrm{mg}$ respectively). In addition, fasting plasma glucose concentrations decreased significantly $(P<0.05)$ over the test period. It is concluded that orally supplied propionate affects both glucose and cholesterol metabolism as judged from lowered urinary glucose excretion, fasting blood glucose and liver cholesterol pools. On the other hand, propionate administered to the hind-gut at a physiologically relevant level reduces the hepatic cholesterol pool.
\end{abstract}

Propionate: Cholesterol: Glucose metabolism

Short-chain fatty acids (SCFA) i.e. acetic, propionate and butyric acids are produced from fermentation of indigestible carbohydrates in the hind-gut. Major sources of indigestible carbohydrates in the diet are dietary fibre, resistant starch and oligosaccharides. With some substrates, for example inulin, considerable amounts of lactic acid are also formed (Levrat et al. 1991). The SCFA are readily absorbed from the large bowel, entering hepatic metabolism or being distributed to more peripheral tissues in the body. Butyric acid is, however, largely utilized by the colonocytes (Cummings \& Macfarlane, 1991), and it has been suggested that it protects against the genesis of colonic diseases (Roediger, 1982; Whitehead et al. 1986). In this respect the lowering of colonic $\mathrm{pH}$ may be beneficial as such (Cummings \& Branch, 1982). In addition, it has been proposed that the SCFA exert specific metabolic effects. Propionic acid, in particular, is discussed in relation to beneficial effects on lipid and glucose metabolism (Anderson \& Bridges, 1984; Wright et al. 1990).

Studies regarding metabolic effects of propionate have been performed mainly in tests with orally supplied propionate (Illman et al. 1988; Venter et al. 1990 a; Todesco et al. 
1991; Boillot et al. 1995) and results from rectal or caecal infusion with SCFA are scarce (Wolever et al. 1991; Beaulieu \& McBurney, 1992; Bach Knudsen \& Canibe, 1993).

There are indications of a decrease in plasma cholesterol concentration following oral administration, and decreased serum cholesterol concentrations were observed in rats fed on diets supplemented with propionate (Illman et al. 1988), or cholesterol and propionate (Chen et al. 1984). In pigs, orally-administered propionate appeared to depress cholesterol synthesis only when tallow was included in the diet (Boila et al. 1981). In contrast, when propionate was infused into the caecum of pigs, increased total serum cholesterol levels were observed by Beaulieu \& McBurney (1992), whereas no impact was noted by others (Bach Knudsen \& Canibe, 1993).

Few studies are available in humans. However, Venter et al. $(1990 a)$ observed an increased serum HDL-cholesterol concentration in healthy subjects after dietary supplementation with propionate, with no effect on total cholesterol concentration. Other observations in humans include studies by Wolever et al. (1991), in which the formation of cholesterol from acetate was inhibited in the presence of propionate during rectal administration of these SCFA, alone or in combination.

Concerning possible effects on glucose metabolism, experiments in animals suggest that propionate stimulates insulin secretion (Brockman, 1982). When propionate was incorporated into bread, postprandial blood glucose and insulin responses were significantly reduced in healthy subjects (Todesco et al. 1991; Liljeberg et al. 1995). Further, when fed to baboons, propionate lowered postprandial blood glucose responses (Venter $e t$ al. $1990 \mathrm{~b}$ ). However, available information also suggests long-term metabolic effects in humans, and dietary supplementation with propionate for 7 weeks decreased fasting serum glucose and reduced maximum insulin increments during a subsequent oral glucose tolerance test (Venter et al. 1990a).

Whether the effect of propionate on glucose and lipid metabolism is mediated by effects in the upper gastrointestinal tract or in the hind-gut is not clear. With respect to lipid metabolism, possible mechanisms might be an inhibition of cholesterol-synthesizing enzymes and/or increased faecal excretion of bile acids. Propionate has been shown to inhibit cholesterol synthesis in isolated rat hepatocytes (Chen et al. 1984; Wright et al. 1990). Studies on rat hepatocytes have further shown that the secretion of bile acids and the activity of cholesterol 7- $\alpha$ hydroxylase $(E C 1.14 .13 .17)$ are increased by propionate, but not with butyrate or acetate (Imaizumi et al. 1992). Hepatic cholesterol level thus appears to be a relevant indicator of potential effects of propionic acid on cholesterol metabolism.

With respect to beneficial effects on glucose metabolism, Todesco et al. (1991) suggested that the reduction seen in postprandial glycaemia following ingestion of propionateenriched bread was caused by an inhibition of the amylolytic activity. Other possible mechanisms include a delay in the rate of gastric emptying in mammals, including man (Blum et al. 1976; H. Liljeberg and I. Björck, unpublished results). In addition, propionic acid has been shown to increase glycolysis and decrease glucose production in isolated rat hepatocytes (Anderson \& Bridges, 1984).

In the present study the possible influence of propionate on glucose and cholesterol metabolism was evaluated in obese hyperinsulinaemic $(\mathrm{fa} / \mathrm{fa})$ rats with a metabolic status resembling that of subjects at risk of developing metabolic disease. Potential effects on cholesterol metabolism were evaluated by analysis of liver cholesterol, and effects on glucose metabolism by measurement of urinary glucose and fasting plasma glucose levels. The diets were formulated to mimic a western-type diet with respect to the distribution of energy from carbohydrate, protein and fat, and contained a high proportion of saturated fat and cholesterol. The test period was $19 \mathrm{~d}$, during which propionate was administered 
orally through the diet or by rectal infusion to enable differentiation of effects mediated in the upper gastrointestinal tract and the hind-gut.

\section{MATERIALS AND METHODS}

\section{Animal experiments}

Diets. The composition of the basal diet is described in Table 1. The diets were formulated to contain high concentrations of cholesterol $(20 \mathrm{~g} / \mathrm{kg})$ and saturated fat $(130 \mathrm{~g} / \mathrm{kg})$, i.e. about $38 \%$ of the energy originated from fat, $17 \%$ from protein and $45 \%$ from carbohydrate. The diets contained only carbohydrates expected to be completely and rapidly absorbed from the rat small intestine, i.e. fully gelatinized maize starch (Snowflake, Cerestar Scandinavia A/S, Holte, Denmark) and glucose (Sigma, St Louis, MO, USA) to prevent interference from SCFA production.

Animals. Male Zucker (fa/fa) rats (Harlan Olac Limited, Bicester, Oxon), characterized by high insulin and lipid levels in blood (Schirardin et al. 1979), were used. The test period was $19 \mathrm{~d}$. The rats, with an initial weight of 350 (SEM 6) g, were divided into three groups of five, and kept individually in metabolic cages (Eggum, 1973) for separate collection of urine and faeces during the last $5 \mathrm{~d}$ (day 15-day 19) of the test period. The feed intake was restricted to $20 \mathrm{~g}$ dry weight $/ \mathrm{d}$, while the rats had free access to water. Urine was collected in flasks containing $2 \mathrm{ml}$ isopropanol to prevent microbial growth, while faeces were collected dry. Both faeces and urine were collected daily and kept frozen at $-20^{\circ}$ until analysed. After the test period, the rats were killed with diethyl ether.

One group of animals was fed on the basal diet only (the control group). A second group was fed on the basal diet, but was infused rectally each day throughout the study with approximately $0.15 \mathrm{~g}$ sodium propionate $(\mathrm{NaPr})(4 \mathrm{mmol} / \mathrm{kg}$ body weight) in an isotonic $\mathrm{NaCl}$ solution $(2.5 \mathrm{ml})$. This amount of propionate corresponds to the quantity which would be expected to be formed from a diet containing $70 \mathrm{~g} / \mathrm{kg}$ completely fermentable carbohydrate (Cummings \& Macfarlane, 1991). The actual dose administered was at maximum $0 \cdot 15 \mathrm{~g} \mathrm{NaPr} / \mathrm{d}$ as losses via the anus could not be avoided. During rectal infusion the rats were lightly anaesthetized with diethyl ether for approximately $5 \mathrm{~min}$ and the propionate solution was administered for a period of 1-2 $\mathrm{min} 100 \mathrm{~mm}$ proximal to the anorectal sphincter. Excretions of urine and faeces during the infusion were carefully collected. Finally, a third group was administered propionate through the diet. This was achieved by exchanging $50 \mathrm{~g} / \mathrm{kg}$ of the starch in the basal diet for $\mathrm{NaPr}$, corresponding to a daily $\mathrm{NaPr}$ intake of approximately $1 \mathrm{~g}(26 \mathrm{mmol} / \mathrm{kg}$ body weight). This level corresponds to the dietary level previously used by others (Boila et al. 1981; Illman et al. 1988; Todesco et al. 1991 ; Liljeberg et al. 1995).

The study was approved by the local ethical committee for animal studies at Lund University.

\section{Sampling and analyses}

Urine was analysed for glucose, whereas in the case of faeces the faecal dry matter (DM) during the last $5 \mathrm{~d}$ of the test period was determined. To determine fasting values of glucose and insulin at the start (day 0) and end (day 20) of the test period, blood was withdrawn from the tail after prior treatment with xylocain. The feed was withheld overnight before blood sampling. Heparin was added to prevent clotting of the blood samples. Plasma was then removed and kept frozen. After killing the animals, the liver was immediately removed, weighed and frozen $\left(-20^{\circ}\right)$ until analysed for total cholesterol.

No significant differences in weight gain, feed intake or DM digestibility could be observed between the three groups. 
Table 1. Composition of the basal diet $(\mathrm{g} / \mathrm{kg}$ on a dry weight basis $(\mathrm{dwb}))$

\begin{tabular}{lc}
\hline \hline Component & $\mathrm{g} / \mathrm{kg}$ (dwb) \\
\hline Casein (ICN Biomedicals Ltd, Oxon) & 199 \\
DL-Methionine (Sigma Chemical Co., St Louis, MO, USA) & 1 \\
Maize oil & 50 \\
Lard & 130 \\
Cholesterol (Merck, Darmstadt, Germany) & 20 \\
Glucose (Sigma) & 100 \\
Maize starch, Snowflake (Cerestar Scandinavia, Holte, A/S Denmark) & 442 \\
Choline chloride (Kebo Lab AB, Stockholm, Sweden) & 2 \\
Mineral mixture* (Hospital Pharmacy, Lund, Sweden) & 48 \\
Vitamin mixture† (Hospital Pharmacy) & 8 \\
\hline \hline
\end{tabular}

* Contained (g/kg dwb): $\mathrm{CuSO}_{4} 0 \cdot 37 ; \mathrm{ZnSO}_{4} .7 \mathrm{H}_{2} \mathrm{O} 1 \cdot 4, \mathrm{KH}_{2} \mathrm{PO}_{4} 332 \cdot 1, \mathrm{NaH}_{2} \mathrm{PO}_{4} .2 \mathrm{H}_{2} \mathrm{O}$ 171.8, $\mathrm{CaCO}_{3}$ 324.4, $\mathrm{KI} 0 \cdot 068, \mathrm{MgSO}_{4} 572, \mathrm{FeSO}_{4} .7 \mathrm{H}_{2} \mathrm{O} 7 \cdot 7, \mathrm{MnSO}_{4} . \mathrm{H}_{2} \mathrm{O} 3 \cdot 4, \mathrm{CoCl}_{2} 0 \cdot 023, \mathrm{NaCl} 101 \cdot 7$.

$\dagger$ Contained $(\mathrm{g} / \mathrm{kg}$ dwb): menadione $0 \cdot 62$, thiamine hydrochloride $2 \cdot 5$, riboflavin $2 \cdot 5$, pyridoxine hydrochloride 1.25 , calcium pantothenate 6.25 , nicotinic acid 6.25 , pteroylmonoglutamic acid 0.25 , inositol $12.5, p$-amino benzoic acid 1.25 , biotin 0.05 , cyanocobalamin 0.00375 , retinol 0.19 , cholecalciferol $0.011, \alpha$-tocopheryl acetate 5 , wheat starch $941 \cdot 25$.

Fasting plasma glucose was analysed with a glucose oxidase $(E C$ 1.1.3.4)-peroxidase (EC 1.11.1.7) reagent (Bruss \& Black, 1978) and insulin with a radio-immunoassay (Heding, 1966). Glucose in urine was analysed, after acetylation, by GLC (Nyman et al. 1990). Total cholesterol in liver tissue was analysed with Sigma kit no. 352-50 (Sigma Chemical Co., St Louis, MO, USA) after extraction with chloroform-methanol (Carlson \& Goldfarb, 1977).

\section{Statistical evaluation}

One-way ANOVA followed by Duncan's procedure for multiple comparison was used to determine significant differences between groups using an SPSS PC + statistical program (V2.0, SPSS Inc., Chicago, IL, USA).

\section{RESULTS AND DISCUSSION \\ Effects on glucose metabolism}

Fasting plasma glucose concentrations at the end of the test period were lower $(P<0 \cdot 01)$ in rats fed on the propionate-supplemented diet than in the control group (Table 2). In addition, in the orally supplemented group there was a decrease over the test period $(P<0.05)$, whereas fasting blood glucose remained unaffected in the control group and the group administered propionate rectally. The fasting plasma insulin levels were high, approximately $200 \mu \mathrm{U} / \mathrm{ml}$, which is higher than the range reported for $\mathrm{fa} / \mathrm{fa}$ rats on a commercial diet (Schirardin et al. 1979) and consistent with a hyperinsulinaemic status. No differences in fasting insulin concentration were obtained.

When measuring glucose excretion in urine during the last $5 \mathrm{~d}$ of the test period, significantly lower excretions were noted in the group fed with propionate $(23 \mathrm{mg})$ $(P<0.05)$, compared with the control group or the group infused rectally $(39 \mathrm{mg}$; Table 2). This was not due to a lower feed intake, which was similar for all groups during the whole test period.

A lowering of fasting blood glucose following dietary supplementation with propionate and the absence of effect on fasting insulin are in agreement with studies in humans by Venter et al. $(1990 \mathrm{a})$. Similar effects of oral propionate were also obtained in rats by Boillot et al. (1995), with no changes in glucose production or whole-body glucose utilization. 
Table 2. Effect of sodium propionate ( $\mathrm{NaPr})$, administered orally or rectally to rats, on fasting plasma glucose concentrations and urinary glucose excretion*

(Mean values with their standard errors for five rats per group)

\begin{tabular}{|c|c|c|c|c|c|c|c|}
\hline \multirow[b]{3}{*}{ Test condition } & \multicolumn{4}{|c|}{ Fasting plasma glucose $(\mathrm{mmol} / \mathrm{l})$} & \multirow{3}{*}{$\begin{array}{c}\text { Statistical } \\
\text { significance } \\
\text { of change } \\
(P<) \text { : }\end{array}$} & \multirow{2}{*}{\multicolumn{2}{|c|}{$\begin{array}{l}\text { Urinary glucose } \\
\text { excretion } \\
\text { (mg/5 d; } \\
\text { days 15-19) }\end{array}$}} \\
\hline & \multicolumn{2}{|c|}{ Start (day 0) } & \multicolumn{2}{|c|}{ End (day 20) } & & & \\
\hline & Mean & SE & Mean & SE & & Mean & $\mathrm{SE}$ \\
\hline Control (basal diet only) & 7.8 & 0.2 & $9 \cdot 3^{\mathrm{n}}$ & 0.4 & NS & $39^{b}$ & 12 \\
\hline $\begin{array}{l}\text { Basal diet + rectal infusion } \\
\text { with } 0.15 \mathrm{~g} \mathrm{NaPr} / \mathrm{d}\end{array}$ & $7 \cdot 6$ & $0 \cdot 2$ & $7 \cdot 9^{\mathrm{ab}}$ & 0.3 & NS & $38^{\mathrm{b}}$ & 4 \\
\hline $\begin{array}{l}\text { Basal diet supplemented } \\
\text { with } 50 \mathrm{~g} \mathrm{NaPr} / \mathrm{kg}\end{array}$ & $6 \cdot 9$ & $0-1$ & $5 \cdot 8^{b}$ & $0 \cdot 1$ & $0 \cdot 05$ & $23^{a}$ & 3 \\
\hline
\end{tabular}

a, b Mean values within a column not sharing a common superscript letter were significantly different $(P<0.05$ or better).

* For details of diets and procedures, see Table 1 and pp. 289-290.

Possible mechanisms for reduced urinary glucose excretion include a delay in the rate of gastric emptying (Blum et al. 1976) or a decreased rate of starch digestion (Todesco et al. 1991), both leading to a blunting of the postprandial glycaemic response. Others have failed to demonstrate a reduced rate of amylolysis of starch in propionate-enriched bread (Liljeberg et al. 1995). Moreover, in that study not only glycaemic response, but in particular the postprandial insulinaemia, was prominently reduced. A blunting of glucose and insulin responses can be expected to suppress plasma free fatty acid (FFA) levels, thus enhancing tissue uptake of glucose (Jenkins et al. 1994). If present, such a mechanism might explain the reduction seen in fasting blood glucose in the present study. Another possible mechanism by which propionate could influence fasting plasma glucose levels and urinary glucose excretion is by inhibiting hepatic glucose production and stimulating hepatic glycolysis (Anderson \& Bridges, 1984). However, as judged from the lack of effect in the case of rectally infused animals, dietary propionate was more effective, thus indicating an effect mainly in the upper gastrointestinal tract, or from propionate absorbed at this site. On the other hand, it should be recalled that the propionate level provided in the diet was six times higher than the dose administered rectally. Further, it should be noted that the fasting plasma insulin levels were not reduced in the propionate-fed group in spite of the markedly lower fasting plasma glucose levels, and it is also known from previous studies that obese fa/fa rats display a highly resistant hyperinsulinaemia (Shafrir, 1992).

\section{Effects on lipid metabolism}

When studying possible effects on liver metabolism, minor differences were found in the concentration of liver cholesterol between groups. On the other hand, the total pools measured at the end of the test period were significantly lower in rats administered propionate rectally $(484 \mathrm{mg})$ or orally $(481 \mathrm{mg})$, compared with the control group $(614 \mathrm{mg})$ $(P<0.01)$ (Table 3). This was due to lower liver weights $(P<0.05)$ in rats fed, or infused rectally, with propionate, 15.3 and $15.5 \mathrm{~g}$, compared with $18.2 \mathrm{~g}$ in the case of the control group (Table 3 ). The reason for this has not been established, but could involve a larger hepatic deposition of fat in the control group, making it more relevant to focus on the pool rather than the concentration.

A lowering of liver cholesterol with orally supplied propionate has also been observed in 
Table 3. Effect of sodium propionate ( $\mathrm{NaPr})$, administered orally or rectally to rats, on liver cholesterol content and liver weight*

(Mean values with their standard errors for five rats per group)

\begin{tabular}{|c|c|c|c|c|c|c|}
\hline \multirow[b]{3}{*}{ Test condition } & \multicolumn{4}{|c|}{ Liver cholesterol } & & \\
\hline & \multicolumn{2}{|c|}{$\begin{array}{c}\text { Concentration } \\
(\mathrm{g} / \mathrm{kg})\end{array}$} & \multicolumn{2}{|c|}{$\begin{array}{c}\text { Pool } \\
\left(\mathrm{mg}_{\text {tot }}\right)\end{array}$} & \multicolumn{2}{|c|}{$\begin{array}{c}\text { Liver } \\
\text { weight (g) }\end{array}$} \\
\hline & Mean & $\mathbf{S E}$ & Mean & SE & Mean & SE \\
\hline Control (basal diet only) & $32 \cdot 8$ & $1 \cdot 1$ & $614^{b}$ & 25 & $18 \cdot 2^{b}$ & 0.6 \\
\hline $\begin{array}{l}\text { Basal diet + rectal infusion } \\
\text { with } 0.15 \mathrm{~g} \mathrm{NaPr} / \mathrm{d}\end{array}$ & $31 \cdot 4$ & $1 \cdot 1$ & $484^{\mathrm{a}}$ & 28 & $15 \cdot 5^{\mathrm{a}}$ & $1 \cdot 0$ \\
\hline $\begin{array}{l}\text { Basal diet supplemented } \\
\text { with } 50 \mathrm{~g} \mathrm{NaPr} / \mathrm{kg}\end{array}$ & $30 \cdot 9$ & 0.8 & $481^{a}$ & 29 & $15 \cdot 3^{\mathrm{a}}$ & 0.7 \\
\hline
\end{tabular}

a, b Mean values within a column with unlike superscript letters were significantly different $(P<0.05$ or better)

* For details of diets and procedures, see Table 1 and pp. 289-290.

other animal studies using hypercholesterolaemic diets high in saturated fat (mean $30 \%$ energy) and supplemented with propionate. Thus, liver cholesterol levels have been shown to decrease in both pigs and baboons (Boila et al. 1981; Venter et al. 1990 b). Further, in pigs, also, plasma cholesterol levels decreased when tallow was included in the diet (Thacker et al. 1981). However, studies are not consistent and other experiments in rats with high-fat diets have failed to demonstrate any effect (Cameron-Smith et al. 1994). Further, with low-fat diets ( $<15 \%$ energy as fat, with no added saturated fat) an increase in cholesterol concentration was found in rat liver tissues by Illman et al. (1988), whereas others reported a decrease following dietary supplementation with propionate (Chen $e t$ al. 1984).

Some studies are also available in humans with orally supplied propionate, indicating beneficial effects on blood lipids. In a long-term study, Venter et al. (1990a) showed that dietary supplementation with propionate increased serum HDL-cholesterol concentrations, whereas no effects were observed on total cholesterol. In another long-term study in men, where propionate was supplied orally $(75 \mathrm{mmol} \mathrm{NaPr} / \mathrm{d})$, a slight lowering of serum total cholesterol levels was found (Amaral et al. 1993).

In the case of rectal and/or caecal infusion with propionate, results are divergent. Thus, in normal pigs fed on hypercholesterolaemic diets, caecal infusion at a level comparable to that used in the present study did not influence plasma cholesterol levels (Bach Knudsen \& Canibe, 1993). In contrast, others have found increased concentrations of total cholesterol in the plasma of pigs (Beaulieu \& McBurney, 1992). In humans, rectally infused propionate appears to lower cholesterol synthesis from acetate, as judged from a lower increment in plasma cholesterol levels with a mixture of acetate and propionate compared with acetate infusion only (Wolever et al. 1991).

The fact that rectal infusion with propionate induced a similar lowering of liver cholesterol at a much lower dosage (about $4 \mathrm{mmol} / \mathrm{kg}$ body weight) compared with dietary supplementation $(26 \mathrm{mmol} / \mathrm{kg}$ ) indicates that the absorption capacity in the caecum and/or colon is high. In this connection it should be noted that whereas dietary propionate was supplied continuously, rectal infusion was performed only once daily. This suggests that propionate, derived from the lower gut, may be a potent moderator of cholesterol 
metabolism. Mechanisms behind the effect of propionate on liver metabolism might be an inhibition of cholesterol-synthesizing enzymes (Chen et al. 1984; Wright et al. 1990) and/or an increase in bile-acid excretion (Imaizumi et al. 1992). In the case of the rectally infused animals one might speculate that the stress caused by anaesthesia could be responsible for the cholesterol-lowering effect by stimulating secretion of cortisol (Becket \& Boyd, 1975). However, fasting blood glucose levels did not change over the experimental period in these animals, as would have been anticipated under such circumstances. This indicates that the potential metabolic effect of anaesthesia was marginal.

In comparison with analysis of blood, changes in lipid metabolism appear to be detected faster in the liver (Önning \& Asp, 1995). This could be one reason for the lack of effects of propionate in studies focusing on plasma-cholesterol levels in short-term experiments. Moreover, the prominent lowering of the liver cholesterol pool with rectally infused or orally supplied propionate and the reduction in fasting plasma glucose and urinary glucose excretion with orally supplied propionate in the present study might be related to the hyperinsulinaemic status of the obese $(\mathrm{fa} / \mathrm{fa}$ ) rats used. Elevated insulin levels as present in the hyperinsulinaemic $(\mathrm{fa} / \mathrm{fa}$ ) rat are known to stimulate hepatic cholesterol synthesis, and reduce glucose tolerance. This makes this type of rat a more sensitive experimental model for investigating factors that improve cholesterol status and glucose tolerance.

It is concluded from the present study in obese rats that dietary propionate markedly reduces the fasting plasma glucose levels with no effects on fasting insulin. This is in accordance with results in humans (Venter et al. 1990a). Further, propionate induced a significant lowering of the liver cholesterol pool and no difference was noted between oral and rectal administration, despite at least a sixfold higher propionate dosage in the case of oral supplementation. This suggests that propionate, when introduced at a physiologically relevant level, in situ, might modulate and improve cholesterol metabolism. Consequently, colonic generation of propionate from a diet rich in soluble viscous dietary fibre or other easily fermentable carbohydrates cannot be disregarded as an important mechanism whereby such carbohydrates improve lipid metabolism.

We thank our friend and colleague Mr Kjell Ohlsson for skilful technical assistance with the animal experiments. This investigation was supported by Nordisk Industrifond (P 88160), Direktör Albert Påhlsson's foundation, Cerealia foundation for research and development, ACO AB and Semper AB, Sweden.

\section{REFERENCES}

Amaral, L., Hoppel, C. \& Stephen, A. M. (1993). Effect of propionate on lipid metabolism in healthy human subjects. In Short Chain Fatty Acids. Abstracts to Falk Symposium no. 73, Strasbourg, France, 1993 , E2. Freiburg, Germany: Falk Foundation.

Anderson, J. W. \& Bridges, S. R. (1984). Short-chain fatty acid fermentation products of plant fiber affect glucose metabolism of isolated rat hepatocytes. Proceedings of the Society for Experimental Biology and Medicine 177, $372-376$.

Bach Knudsen, K. E. \& Canibe, N. (1993). Changes in pig plasma lipids to dietary cholesterol, source and level of dietary fibre and caecal infusion of propionate - mechanism of action of dietary fibre on lipid and cholesterol metabolism. In Cost 92. Metabolic and Physiological Aspects of Dietary Fibre in Food. Proceedings of a Workshop held in Carry le Rouet, Marseille, France, October 23 1993, pp. 123-130 [D. Lairon, editor]. Luxembourg: Commission of the European Communities, Directorate-General XIII.

Beaulieu, K. E. \& McBurney, M. I. (1992). Changes in pig serum lipids, nutrient digestibility and sterol excretion during cecal infusion of propionate. Journal of Nutrition 122, 241-245.

Becket, G. J. \& Boyd, G. S. (1975). The effect of dietary rape-seed oil on cholesterol-ester metabolism and cholesterol-ester-hydrolase activity in the rat adrenal. European Journal of Biochemistry 53, 335-342.

Blum, A. L., Hegglin, J., Krejs, G. J., Largiadér, F., Säuberli, H. \& Schmid, P. (1976). Gastric emptying of organic acids in the dog. Journal of Physiology 261, 285-299.

Boila, R. J., Salomons, M. O., Milligan, L. P. \& Aherne, F. X. (1981). The effect of dietary propionic acid on cholesterol synthesis in swine. Nutrition Reports International 23, 1113-1120. 
Boillot, J., Alamowitch, C., Berger, A.-M., Luo, J., Bruzzo, F., Bornet, F. R. J. \& Slama, G. (1995). Effects of dietary propionate on hepatic glucose production, carbohydrate and lipid metabolism in normal rats. British Journal of Nutrition 73, 241-251.

Brockman, R. P. (1982). Insulin and glucagon responses in plasma to intraportal infusions of propionate and butyrate in sheep (Ovis aries). Comparative Biochemistry and Physiology A 73, 237-238.

Bruss, M. \& Black, A. L. (1978). Enzymatic microdetermination of glycogen. Analytical Biochemistry 84, $309-312$.

Cameron-Smith, D., Collier, G. R. \& O'Dea, K. (1994). Effect of propionate on in vivo carbohydrate metabolism in streptozocin-induced diabetic rats. Metabolism 43, 728-734.

Carlson, S. E. \& Goldfarb, S. (1977). A sensitive enzymatic method for the determination of free and esterified tissue cholesterol. Clinica Chimica Acta 79, 575-582.

Chen, W. L., Anderson, J. W. \& Jennings, D. (1984). Propionate may mediate the hypocholesterolemic effect of certain soluble plant fibres in cholesterol fed rats. Proceedings of the Society for Experimental Biology and Medicine 175, 215-218.

Cummings, J. H. \& Branch, W. J. (1982). Postulated mechanisms whereby fiber may protect against large bowel cancer. In Dietary Fiber in Health and Disease, pp. 313-325 [G. V. Vahouny and D. Kritchevsky, editors]. New York and London: Plenum Press.

Cummings, J. H. \& Macfarlane, G. T. (1991). The control and consequences of bacterial fermentation in the human colon. Journal of Applied Bacteriology 70, 443-459.

Eggum, B. O. (1973). A study of certain factors influencing protein utilization in rats and pigs. PhD Thesis, National Institute of Animal Science, Copenhagen, Denmark.

Heding, L. A. (1966). A simplified insulin radioimmunoassay method. In Labelled Proteins in Tracer Studies, pp. 345-350 [L. Donato, G. Milhaud and J. Sirchis, editors]. Brussels: Euroatom.

Illman, R. J., Topping, D. L., McIntosh, G. H., Trimble, R. P., Storer, G. B., Taylor, M. N. \& Cheng, B.-Q. (1988). Hypocholesterolaemic effects of dietary propionate: studies in whole animals and perfused rat liver. Annals of Nutrition and Metabolism 32, 97-107.

Imaizumi, K., Hirata, K., Yasni, S. \& Sugano, M. (1992). Propionate enhances synthesis and secretion of bile acids in primary cultured rat hepatocytes via succinyl CoA. Bioscience Biotechnology Biochemistry 56, 1894-1896.

Jenkins, D., Jenkins, A., Wolever, T., Vuksan, V., Venket Rao, A., Thompson, L. \& Josse, G. (1994). Low glycemic index : lente carbohydrates and physiological effects of altered food frequency. American Journal of Clinical Nutrition 59, 706S-709S.

Levrat, M.-A., Rémésy, C. \& Demigné, C. (1991). High propionic acid fermentation and mineral accumulation in the caecum of rats adapted to high levels of inulin. Journal of Nutrition 121, 1730-1737.

Liljeberg, H., Lönner, C. \& Björck, I. (1995). Sourdough fermentation or addition of organic acids/salts to bread improves nutritional properties of starch in healthy subjects. Journal of Nutrition 125, 1503-1511.

Nyman, M., Schweizer, T. F., Tyrén, S., Reimann, S. \& Asp, N.-G. (1990). Fermentation of vegetable fiber in the intestinal tract of rats and effects on faecal bulking and bile acid excretion. Journal of Nutrition 120, 459-466.

Önning, G. \& Asp, N.-G. (1995). Effect of oat saponins on plasma and liver lipids in gerbils (Meriones unguiculatus) and rats. British Journal of Nutrition 73, 275-286.

Roediger, W. E. W. (1982). Utilization of nutrients by isolated epithelial cells of the rat colon. Gastroenterology $83,424-429$.

Schirardin, H., Bach, A., Schaeffer, A., Bauer, M. \& Weryha, A. (1979). Biological parameters of the blood in the genetically obese Zucker rat. Archives Internationales de Physiologie de Biochemie 87, 275-289.

Shafrir, E. (1992). Animal models of non-insulin dependent diabetes. Diabetes Metabolism Reviews 8, $179-208$.

Thacker, P. A., Salomons, M. O., Aherne, F. X., Milligan, L. P. \& Bowland, J. P. (1981). Influence of propionic acid on the cholesterol metabolism of pigs fed hypercholesterolemic diets. Canadian Journal of Animal Science 61, 969-975.

Todesco, T., Venketshwer, R., Bosello, O. \& Jenkins, D. J. A. (1991). Propionate lowers blood glucose and alters lipid metabolism in healthy subjects. American Journal of Clinical Nutrition 54, 860-865.

Venter, C. S., Vorster, H. H. \& Cummings, J. H. (1990a). Effects of dietary propionate on carbohydrate and lipid metabolism in healthy volunteers. American Journal of Gastroenterology 85, 549-553.

Venter, C. S., Vorster, H. H. \& Van Der Nest, D. G. (1990b). Comparison between physiological effects of konjac-glucomannan and propionate in baboons fed 'Western' diets. Journal of Nutrition 120, $1046-1053$.

Whitehead, R. H., Young, G. P. \& Bhatal, P. S. (1986). Effects of short chain fatty acids on a new human colon carcinoma cell line (LIM1215). Gut 27, 1457-1463.

Wolever, T. M. S., Spadfora, P. \& Eshuis, H. (1991). Interaction between colonic acetate and propionate in humans. American Journal of Clinical Nutrition 53, 681-687.

Wright, R. S., Anderson, J. W. \& Bridges, S. R. (1990). Propionate inhibits hepatocyte lipid synthesis (43113). Proceedings of the Society for Experimental Biology and Medicine 195, 26-29. 